\title{
Agreement Errors in Learner Corpora across CEFR: A Computer-Aided Error Analysis of Greek and Turkish EFL Learners Written Productions
}

\author{
Cem Can \\ Correspondence: Cem Can, Cukurova University, Faculty of Education, ELT Department, Turkey. \\ Received: March 1, 2018 \\ Accepted: March 25, $2018 \quad$ Online Published: March 31, 2018 \\ doi:10.11114/jets.v6i5.3064 \\ URL: https://doi.org/10.11114/jets.v6i5.3064
}

\begin{abstract}
This paper illustrates the use of learner corpus data (extracted from Cambridge Learner Corpus - CLC) to carry out an error analysis to investigate authentic learner errors and their respective frequencies in terms of types and tokens as well as contexts in which they regularly occur across four distinct proficiency levels, B1-B2; C1-C2, as defined by Common European Framework of Reference for Languages (henceforth CEFR) (Council of Europe, 2001). As a variety of learner corpora compiled by researchers become relatively accessible, it is possible to explore interlanguage errors and conduct error analysis (EA) on learner-generated texts. The necessity to cogitate over these authentic learner errors in designing foreign language learning programs and remedial teaching materials has been widely emphasized by many researchers (see e.g., Juozulynas, 1994; Mitton, 1996; Cowan, Choi, \& Kim, 2003; Ndiaye \& Vandeventer Faltin, 2003; Allerton et al., 2004). This study aims at conducting a corpus-based error analysis of agreement errors to reveal the related error categories between Greek and Turkish EFL learners, the distribution of agreement errors along the B1 - C2 proficiency range according to CEFR, and the distribution of agreement error types in respect of the L1 of the learners. The data analyzed in this study is extracted from the Cambridge Learner Corpus (CLC), the largest annotated test performance corpus which enables the investigation of the linguistic and rhetorical features of the learner performances in the above stated proficiency bands. The findings from this study reveal that, across B1-C2 proficiency levels and across different registers and genres, the most common agreement error categories by the frequency in which they occur are Verb Agreement (AGV), Noun Agreement (AGN), Anaphor Agreement (AGA), Determiner Agreement (AGD), Agreement Error (AG), and Quantifier Agreement (AGQ) errors. This study's approach uses the techniques of computer corpus linguistics and follows the steps of the Error Analysis framework proposed by Corder (1971): identification, description, classification and explanation of errors.
\end{abstract}

Keywords: learner corpora, agreement errors, corpus-based error analysis, Turkish EFL learners, Greek EFL learners

\section{Introduction}

Being integral parts of foreign language learning continuum as systemic formations, errors characterize the linguistic competence and may help reveal clues about EFL learners' learning strategies. Hence error analysis is a rational course of action to find out whether the semantic content and the linguistic form of learners' communicative performances are erroneous or deviant from the norms and to reflect upon them. This action could be executed by examining anecdotal evidence or by classroom observation (Swan \& Smith 2001; Kizıl \& Kilimci, 2014b). However, as it encompasses a large number of examples of comprehensive range of error types, a learner corpus is a more dependable option to investigate the (relatively) naturally occurring learner errors. Compiled in a systematic manner, it enables the researchers to target specific error typologies of learners from various mother tongue backgrounds. Having a specific focus, such specialized corpora could serve as useful markers for teaching foreign languages. For example, "descriptions of structure, reliable models of usage, how words and phrases are translated," determining the crucial components of a syllabus, and identifying learners' errors can all be developed and/or supported by focusing on specific genres and subgenres (Sinclair, 2001, p. xiii).

Although they might display subtle differences in terms of their methodologies, theoretical assumptions, data and terminology, Contrastive Analysis (CA) and Error Analysis (EA) studies in Second Language Acquisition pursue the same pedagogical goal, which is the scientific study of learner language to understand the language learning processes better. The most evident distinction between them is found in their approach to the learner's performance and the errors. 
While CA studies intrinsically do not take any position on these issues, traditional EA considers errors to be detrimental and tries to eliminate them. On the other hand, adapting the core principles of interlanguage (IL) according to which the deviations from the TL norms are considered as integral components and indicators of the learner's system, computer-aided error analysis, based on learner corpora, "represents a major improvement over traditional EA, not least because instead of considering errors in isolation, but also it sees them as part of a system which includes both correct and incorrect uses" (Gilquin and Granger, 2015, p.427), combining the underlying principles of IL and EA. Commenting on the use of learner corpus based error analysis and the weaknesses of traditional error analysis, Ellis (1994) states that "the importance of collecting well-defined samples of learner language so that clear statements can be made regarding what kinds of errors the learners produce and under what conditions" and claims that "many EA studies have not paid enough attention to these factors, with the result that they are difficult to interpret and almost impossible to replicate" (p. 49). Commenting on these setbacks, Dagneaux et al., (1998) lists five limitations pertaining to the nature of the data and related error typologies used by traditional EA and:

- Limitation 1: EA is based on heterogeneous learner data;

- Limitation 2: EA categories are fuzzy;

- Limitation 3: EA cannot cater for phenomena such as avoidance;

- Limitation 4: EA is restricted to what the learner cannot do;

- Limitation 5: EA gives a static picture of L2 learning (p. 164).

Within the same line of reasoning, Schachter (1974) also criticizes EA stating that it can only be used to identify and analyze errors that learners actually produce and ignores potential errors that learners do not make because they avoid difficult structures. Supporting these claims, Gilquin (2007) asserts that traditional error analysis results could reveal only a partial picture of the learners' proficiency and target-like language use is much more than the absence of errors. She emphasizes that "[A]n error analysis ... only lifts a corner of the veil. Equally important are indications as to what learners get right, what they underuse and what they overuse" (2007, p.288). Due to the above-mentioned limitations, learner-corpus-based approach to error analysis has been considered as a new direction in the field with its pedagogical implications being perceptible as a useful guidance for Foreign Language (FL) teaching.

The researches on the variation of errors across the language proficiency levels reveal contradictory results. The general assumption in this regard is that the learners to make fewer errors as their proficiency level increases and the errors are related to proficiency (Engber, 1995; Grant \& Ginther, 2000; Kiz1l \& Kilimci, 2014a; Olsen, 1999). On the other hand, some studies reveal that errors are quite common even at the advanced level (e.g. Dagneaux et al. 1998). Moreover, it is usually expected that learners to make various types of errors as they get further. In her longitudinal study, Chamot (1987) reveals a great deal of fluctuations in the error typology across the levels and persistence related to some errors. Some studies state that the further proficiency level the learners attain, the lower the L1 influence would be (Taylor, 1975). On the other hand, some other research studies claim that that some errors can only appear at a higher level of proficiency (Kellerman, 1983).

Grammatical agreement is a phenomenon in natural languages in which the form of one word or morpheme covaries with the form of another word or phrase in the sentence. Greek and Turkish are inflectionally rich languages (Clairis \& Babiniotis 1998, 1999; Holton, Mackridge \& Philippaki-Warburton 1997; Kornfilt, 1997). They both have rich agreement systems. Turkish verbs, marked by suffixes, agree in person and number with their subjects. In Greek, all words in the same noun phrase and modifying the noun agree with each other in gender, number and case. Thus, all declinable modifiers (articles, adjectives, numerals and determiners), except possessive pronouns, indicate in their inflection their gender, number and case agreement with the noun they modify (Holton, Mackridge \& Philippaki-Warburton 1997). On the other hand, modern English does not have a particularly rich system of agreement when compared to Greek and Turkish. Usually, the count-mass distinction for nouns is at the core of the problem of EFL learners with respect to subject-verb agreement. The problematic -s affix requires a great deal of knowledge grammar. First, third person singular $-\mathrm{s}$ is only placed when the subject NP fits a definite criterion. It can only be (a) a 3rd-person, singular pronoun (for example: she, he, it, or one), (b) a proper noun (the name of an individual entity, not a group), or (c) a common noun referring to a concept or entity which is both countable and singular (Escure, \& Schwegler, 2004). Second, and making issue even more intricate, the third person -s is inserted when the grammatical subject is a non-count noun as well. First, learners are supposed to decide whether a noun in the subject NP slot is countable or uncountable, and then, if it is countable, whether it is singular or plural. Moreover, it is another issue to be sufficiently aware of the idiosyncratic grammatical properties.

\section{Methodology}

Bardovi-Harlig and Bofman (1989) states that many of the studies of grammatical development in second language 
acquisition could be classified into two:

(a) studies that examine formal features and

(b) studies that seek to gauge overall progress by a developmental index. (P. 18)

The current study falls into the second category. It aims at detecting and analyzing the interlanguage characteristics of developmental agreement errors in Turkish EFL learners using a substantial body of written data. As Biber, Conrad, and Reppen (1998) emphasize, the studies using large data sets may lead to significant improvements in the understanding of language acquisition. For this reason, analyzing Cambridge Learner Corpus (CLC), probably the largest annotated learner corpus $(29,266,800$ words), this study aims to contribute to the emerging body of research in learner-corpus-based error analysis and foreign language learning with its investigation of agreement errors of Turkish and Greek learners of English as a Foreign Language (EFL). The corpus used in this study is the Turkish and Greek EFL learner subcorpora of CLC. CLC consists of the texts produced by learners from 138 different mother tongue backgrounds as part of the University of Cambridge English for Speakers of Other Languages (ESOL) examinations. All the learner errors are annotated, and each text is provided with the metadata such as the mother tongue background, nationality, age, gender, CEFR level of the learner, format and the register of the text, and the test's name.

The Turkish and Greek EFL learner subcorpora extracted from CLC consist of 1,841,510 words in total. The breakdown of the corpus is as follows.

Table 1. The breakdown of Turkish and Greek EFL learner subcorpora

\begin{tabular}{|c|c|c|c|c|}
\hline L1 & Corpus Size & Exam & Years & Exam Format \\
\hline \multirow[t]{6}{*}{ Greek } & CEFR Levels: & & \multirow{12}{*}{$1993-2012$} & - Composition/assay \\
\hline & B1: 161,361 & & & - Letter/reference \\
\hline & B2: 449,422 & & & - Note/email/memo \\
\hline & $\mathrm{C} 1: 376,131$ & & & - Story \\
\hline & C2: 342,544 & & & - Formal \\
\hline & Total: $1,329,458$ & $\begin{array}{l}\text { CAE } \\
\text { CPE }\end{array}$ & & $\begin{array}{l}\text { - Informal } \\
\text { - Neutral/unmarked }\end{array}$ \\
\hline \multirow{6}{*}{ Turkish } & CEFR Levels: & FCE & & - Advice \\
\hline & B1: 165,482 & PET & & - Application/response \\
\hline & B2: 195,268 & & & - Argumentative/opinion \\
\hline & C1: 106,363 & & & - Business \\
\hline & C2: 44,939 & & & $\begin{array}{l}\text { - Complaint/apology/response } \\
\text { - Critical }\end{array}$ \\
\hline & Total: 512,052 & & & $\begin{array}{l}\text { - Descriptive/creative/autobiographical } \\
\text { - Informative/news }\end{array}$ \\
\hline
\end{tabular}

As presented in the table, the corpus data includes learner generated texts from Cambridge University examinations administered between $1993-2012$ in various genres.

According to Granger (2003), an ideal error taxonomy to be used in error analysis should be consistent, informative, flexible and reusable. As stated by (Heift \& Schulze, 2012), most error taxonomies have the following problems:

- Coverage: some errors may be left unclassified when the taxonomy is applied to more texts or future analysis, due to the impossibility of error anticipation;

- Homogeneity: it is difficult to achieve a comprehensive and meaningful description of errors; and,

- Classification characteristics: many categories are language dependent or cannot be easily distinguished

In this study, the agreement error typology used is based on the one developed by CLC. Learner errors in CLC are tagged using the following convention (CUP, 2014, p. 14-15):

$<\#$ CODE > wrong word|corrected word</\#CODE>

The agreement error codes are based on a three-letter coding system (in which the first two letters (AG) represents the type of error, while the third letter identifies the word class. The errors tagged using this convention and the related examples are as follow:

- Agreement Error (AG): The correct words have been used but they do not agree grammatically with their coordinates.

I could not breathe. <\#AG> Those were / That was </\#AG> not good news. 
- Anaphor agreement error (AGA): A pronoun does not agree with the item to which it refers. This error code is also used for errors of gender agreement.

If we can't stop $\langle \# \boldsymbol{A G A}>\mathbf{i t} /$ them $\langle/ \# \boldsymbol{A G A}\rangle$ then the car is a danger.

- Determiner agreement error (AGD): A possessive or demonstrative adjective does not agree in number. This code is also used for errors of gender agreement and when the error form is a quantifier and the corrected form is a determiner.

I wanted to sleep 〈\#AGD> those /DT | that 〈\#AGD> night, because I would 〈\#TV〉 get | be getting $\langle/ \# T V\rangle$ up at 8.00 pm to go to my volleyball match.

- Noun agreement error (AGN): The noun does not agree in number.

It was the best <\#AGN> holidays /NNS | holiday </\#AGN> of my life.

- Quantifier agreement error (AGQ): The quantifier does not agree in number. It is also used when the error form is a determiner and the corrected form is a quantifier

Suddenly three policemen rushed in and immobilised him while $\langle \# A G Q\rangle$ other $/ J J \mid$ another $\langle/ \# A G Q\rangle$ two pointed $\langle \# M T\rangle \mid$ at $\langle/ \# M T\rangle$ him with guns.

- Verb agreement error (AGV): The verb does not agree with the subject

Why $\langle \# W\rangle I ' m \mid$ am I $\langle/ \# W\rangle\langle \# M D\rangle \mid$ the $\langle/ \# M D\rangle$ only person in the world that $/ V H P \mid$ has $\langle \# A G V\rangle$ have $</ \# A G V>$ such bad luck.

\section{Data Analysis}

The overall analysis of the agreement errors made by Turkish and Greek learners regardless of the proficiency levels revealed that there are 2184 errors in Turkish learners' subcorpus of CLC and 2552 in Greek learners' subcorpus. Graph 1 presents the breakdown of these errors according to the agreement error categories.

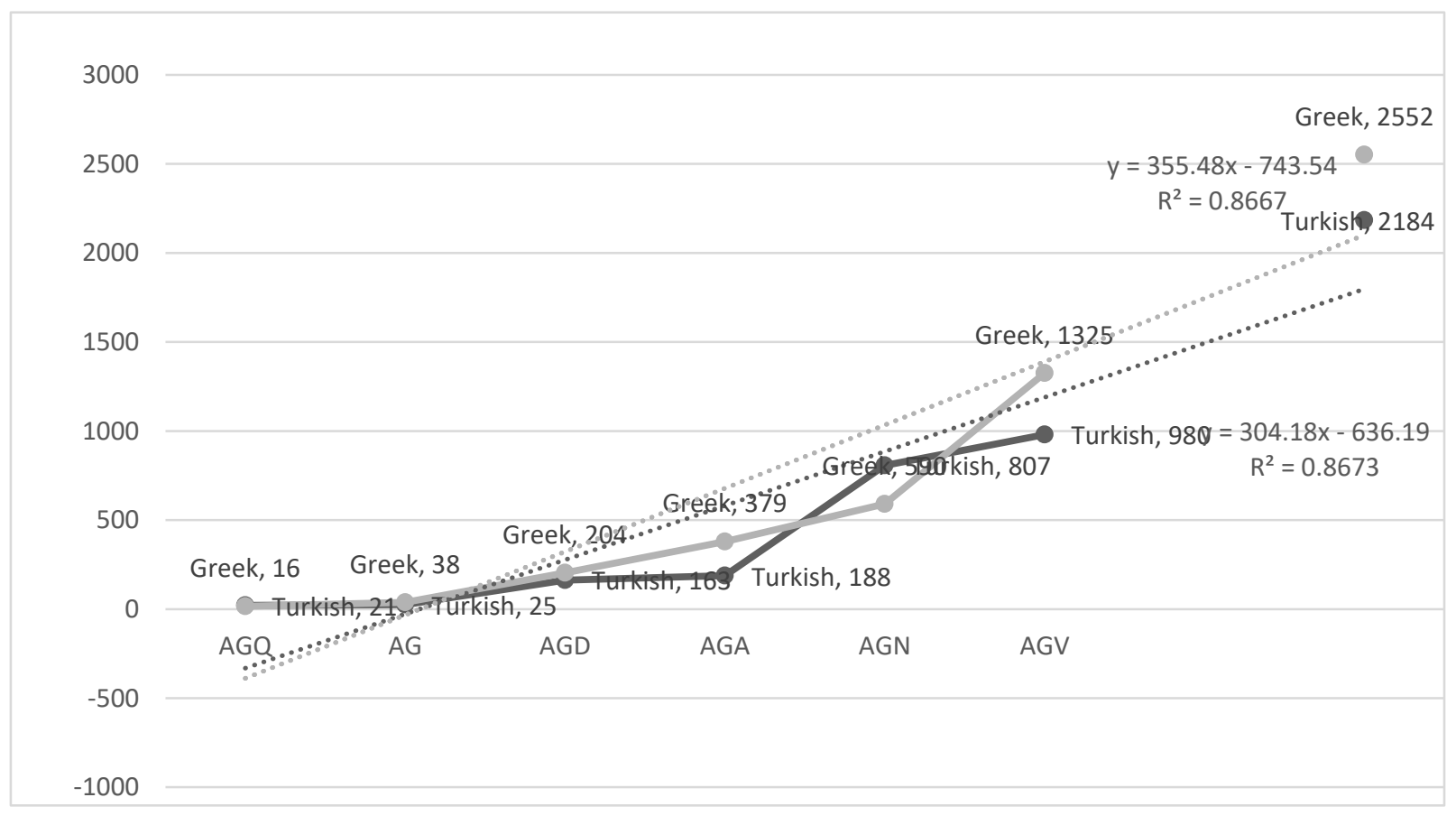

Graph 1 . The breakdown of agreement errors by Turkish and Greek Learners

As displayed in Graph 1, the most common error category across the proficiency levels is related with the verb agreement error (AGV). This error typology is followed by noun agreement error (AGN). These two most common error categories are followed by anaphor agreement error (AGA), determiner agreement error (AGD), agreement error $(\mathrm{AG})$, and quantifier agreement (AGQ) errors.

This graph presents a bird-eye view to the agreement errors of Turkish and Greek EFL learners from B1 to C2 English language proficiency levels. In order to reveal the distribution of these error typologies according to each proficiency band of the learners, a further analysis has been carried out based on the CEFR levels. 
Table 2. Distribution of Agreement Error Typologies

\begin{tabular}{|c|c|c|c|c|c|c|c|c|}
\hline \multirow{2}{*}{$\begin{array}{c}\text { Corpus Size } \\
\text { Greek }\end{array}$} & \multirow{2}{*}{$\begin{array}{c}\text { Corpus Size } \\
\text { Turkish }\end{array}$} & \multirow[t]{2}{*}{ CEFR Level } & \multicolumn{6}{|c|}{ Agreement Error Typologies } \\
\hline & & & AGQ & AG & AGD & AGA & AGN & AGV \\
\hline \multirow[t]{2}{*}{610.783} & \multirow[t]{2}{*}{360.750} & $\begin{array}{l}\text { Turkish } \\
\text { B1 - B2 }\end{array}$ & 18 & 24 & 126 & 150 & 666 & 792 \\
\hline & & $\begin{array}{l}\text { Greek } \\
\text { B1 -B2 }\end{array}$ & 8 & 14 & 91 & 187 & 307 & 777 \\
\hline \multirow[t]{2}{*}{718.675} & \multirow[t]{2}{*}{151.302} & $\begin{array}{l}\text { Turkish } \\
\text { C1 - C2 } \\
\end{array}$ & 3 & 1 & 37 & 38 & 141 & 188 \\
\hline & & $\begin{array}{c}\text { Greek } \\
\text { C1 - C2 }\end{array}$ & 8 & 24 & 113 & 192 & 283 & 548 \\
\hline \multirow{2}{*}{$\begin{array}{l}\text { Total } \\
1,329,458\end{array}$} & \multirow[t]{2}{*}{$\begin{array}{l}\text { Total } \\
512,052\end{array}$} & $\begin{array}{c}\text { Turkish } \\
\text { Total }\end{array}$ & 21 & 25 & 163 & 188 & 807 & 980 \\
\hline & & $\begin{array}{c}\text { Greek } \\
\text { Total } \\
\end{array}$ & 11 & 38 & 204 & 379 & 590 & 1325 \\
\hline
\end{tabular}

When the breakdown of the agreement errors according to the proficiency levels of the learners in Table 2 examined, it is inferred that the ranking of the agreement errors does not change within the proficiency levels. As the table displays the number of the errors for each agreement error category for each proficiency level and the corpus sizes are varied in each corpus, it is not possible to claim any statistical difference among the levels. For this reason, a log-likelihood (LL) analysis has been run to compare the error frequencies by normalizing the corpus sizes. Table 3 displays the LL results for the agreement errors between Turkish and Greek EFL learners according to CEFR proficiency levels.

Table 3. Log-likelihood results (Turkish EFL Learners vs. Greek EFL Learners)

\begin{tabular}{|c|c|c|c|c|c|c|c|c|}
\hline \multirow[t]{2}{*}{ Error Typology } & \multicolumn{2}{|c|}{ Freq. in B1-B2 } & \multirow[t]{2}{*}{$\mathbf{L L}$} & \multirow[t]{2}{*}{ Significance } & \multicolumn{2}{|c|}{ Freq. in C1-C2 } & \multirow[t]{2}{*}{$\mathbf{L L}$} & \multirow[t]{2}{*}{ Significance } \\
\hline & Turkish & Greek & & & Turkish & Greek & & \\
\hline AGQ & 18 & 8 & 19,19 & $0,000 * * *+$ & 3 & 8 & 0,00 & $0,968-$ \\
\hline $\mathrm{AG}$ & 24 & 14 & 20,54 & $0,000 * * *+$ & 1 & 24 & 9,80 & $0,002 * *$ \\
\hline AGD & 126 & 91 & 86,68 & $0,000 * * *+$ & 37 & 113 & 0,75 & $0,385-$ \\
\hline AGA & 150 & 187 & 42,72 & $0,000 * * *+$ & 38 & 92 & 0,13 & $0,718+$ \\
\hline $\mathrm{AGN}$ & 666 & 307 & 691,67 & $0,000 * * *+$ & 141 & 283 & 6,05 & $0,014 *+$ \\
\hline $\mathrm{AGV}$ & 792 & 777 & 358,75 & $0,000 * * *+$ & 188 & 548 & 1,91 & $0,167-$ \\
\hline
\end{tabular}

According to the LL results, Turkish learners within the B1-B2 proficiency range make significantly more errors in all agreement error typologies than Greek EFL learners within the same proficiency band. In both Turkish and Greek learners, the number of these errors decrease as the learners' proficiency level improves but the ranking of the error typologies does not change. In $\mathrm{C} 1-\mathrm{C} 2$ proficiency range, Greek learners seem to be making more agreement errors except AGA and AGN categories. When we examine the frequencies of the errors, AGN and AGV categories seem to be the most persistent errors in both groups of learners. These persistent error typologies are illustrated as follow:

\section{Turkish B1 - Threshold}

Firstly, <\#RP> How $\mid$ how $</ \# R P>$ much does it $<\# A G V>$ costs $/$ VVZ $\mid$ cost $<$ \#AGV $><\# M T>\mid$ for $</ \# M T><$ $\# \mathrm{MD}>\mid \mathrm{a}</ \# \mathrm{MD}>$ double room?

\section{Greek B1 - Threshold}

This <\#AGV> bring | brings </\#AGV> us <\#RT> in | into </\#RT> a very difficult situation.

\section{Turkish B2 - Vantage}

Beside $\mid$ Also </\#RY>, <\#AGV> is /VBZ | are </\#AGV> there any sports or gym activities in the hotel?

\section{Greek B2 - Vantage}

To my regret <\#MP> |, </\#MP> I realized that most of the information provided <\#AGV> were | was $</ \# \mathbf{A G V}>$ not true.

\section{Turkish C1 - Effective Operational Proficiency}

Every <\#AGN> children | child </\#AGN><\#AGV> want /VVP | wants </\#AGV> to become a football play er when they grown up.

\section{Greek C1 - Effective Operational Proficiency}

The money from the foreign states $<\# A G V>$ come $\mid$ comes $</ \# A G V>\ldots .$.

Turkish C2 - Mastery

Giving value to things <\#AGV> make /VVP | makes </\#AGV> life more interesting. 


\section{Greek C2 - Mastery}

- Piggy supports Ralph all the time and his wise $\langle \# C N>$ advices $|$ advice $\langle$ \#CN $\rangle\langle \# A G V\rangle$ save $\mid$ saves $</ \# \mathbf{A G V}>$ them from trouble.

- This is an extremely negative phenomenon which causes even more <\#AGN> problem $\mid$ problems $</ \#$ AGN $><\#$ RT $>$ to $\mid$ for $\langle/ \# R T>$ them.

According to these results that majority of the students have committed errors in subject-verb agreement especially in verb agreement of number and followed by verb agreement of person. The learners have tried to avoid syntactic constructions including the agreement with coordinated subject, agreement with indefinite expressions of amount and also notional agreement and proximity.

In their study with Malaysian EFL learners, Stapa and Izaha (2010) also observes that these learners also experience difficulties in subject-verb agreement because in their L1 which is Bahasa Malaysia, there is no such rule regarding subject-verb agreement. They state that, even at very advance levels of proficiency, Malaysian learners still have these persistent errors in subject-verb agreement. Stapa and Izaha (2010) categorize these verb agreement as follow:

- the subject-verb agreement of person,

- the subject-verb agreement of number,

- the subject-verb agreement of subject,

- the agreement with coordinated subject and the notional agreement and proximity.

\subsection{Source of Errors: Inter-/intra-Lingual?}

In error analysis studies, the sources of errors have traditionally been identified by two transfer issues, namely inter-lingual, stemming from mother tongue interferences, and intra-lingual, belonging to interlanguage properties which might lead us think about universal errors in this regard. Referring to the latter, Ellis (1997) opines that these errors reflect the attempts to make the task of learning and using the target language simpler in interlanguage continuum by simplification and overgeneralization. These systemic formations in interlanguage are common in the productions of foreign language learners, regardless of their mother tongue backgrounds.

In this study, to find out whether the agreement errors stem from mother tongue backgrounds or interlanguage universals, an error analysis has also been conducted for all the learners, available in CLC, coming from 138 first language backgrounds. Table 4 displays the related findings.

Table 4. An Overall Error Analysis of EFL Learners from 138 Mother Tongue Backgrounds for Agreement Errors in CLC $(29,266,800$ words $)$

\begin{tabular}{l|l}
\hline Error Category & Frequency \\
\hline \#AGV & 60,876 \\
\hline \#AGN & 37,163 \\
\hline \#AGA & 12,203 \\
\hline \#AGD & 9,349 \\
\hline \#AG & 3,509 \\
\hline \#AGQ & 1,532 \\
\hline
\end{tabular}

As could be deduced from Table 4, there is consistency in the ranking of the frequency of agreement errors across error typologies when compared to Turkish and Greek EFL learners' leading us consider these universal systemic formations in English as an interlanguage. So, these intra-lingual errors seem to be resulting from faulty or partial learning of the target language rather than mother tongue interference. These could also originate from the influence of one target language property upon another. Considering these findings, it might be propounded that intra-lingual errors, interlanguage properties / universals, emerge as a natural learning process of learners' attempt to construct concepts and hypotheses about the target language from their limited experience with it. Richards (1971) also consider these as "items produced by the learner which reflected not the structure of the mother tongue, but generalization based on partial exposure to the target language. The foreign language learner, attempts to "derive the rules behind the data to which he / she has been exposed, and may develop hypothesis that correspond neither to the mother tongue nor the target language" (Richards, 1971, p.6).

\section{Conclusion}

The nature of error analysis could accommodate both diagnostic and prognostic qualities at the same time. As it gives us hints pertaining to the currents state of interlanguage, it is diagnostic (Corder, 1967). As it also advises curriculum and material developer to reorient language learning materials on the basis of the learners' current problems, it is prognostic. Performing error analysis at systematic intervals enables us to pinpoint the areas that need reinforcement in teaching. 
This study has been conducted to reveal the agreement errors made by Turkish and Greek EFL learners from B1 to C2 proficiency levels. According to the findings of the study, the most common agreement error categories are Verb Agreement (AGV), Noun Agreement (AGN), Anaphor Agreement (AGA), Determiner Agreement (AGD), Agreement Error (AG), and Quantifier Agreement (AGQ) errors according to their frequencies of occurrence in the corpora.

The following recommendations for EFL teachers could be made based on the findings of this study:

- Conscious raising techniques could be implemented to make students more sensitive to subject/verb agreement in the linguistics input surrounding them. For example, the more they notice the third person s' in classroom setting and re-notice it outside the classroom, the more likely they are to reconstruct their interlanguage properties relevant with this feature.

- Training to monitor their production might have positive contributions to their long-term overall accuracy.

- Foreign language teaching interwoven with communicative and interactional competencies enable students use the target language in natural settings.

- EFL teachers equipped with the skills of applying data-driven, corpus-based, teaching techniques, are advised to provide authentic materials as many as possible for students.

- Teachers should also monitor students' written and oral productions to provide them with the required assistance when situation demands as well as carry out on the spot correction or emphasize the issues where students have problems.

- Classroom activities such as debate, quiz, drama, group discussions, and tutorials could be organized to familiarize students with correct use of English language. When learners have more opportunities to be exposed to the conventionalized structures and idiomatic expressions, they are more likely to internalize them and utilize them in their language production.

\section{References}

Allerton, D. J., Tschichold, C., \& Wieser, J. (Eds.), (2004). Linguistics, Language Learning and Language Teaching. Schwabe, Basel, Switzerland.

Bardovi-Harlig, K., \& Bofman, T. (1989). Attainment of Syntactic and Morphological Accuracy by Advanced Language Learners. Studies in Second Language Acquisition, 11, 17-34. https://doi.org/10.1017/S0272263100007816

Biber, D., Conrad, S., \& Reppen, R. (1998). Corpus linguistics: Investigating language structure and use. Cambridge: Cambridge University Press. https://doi.org/10.1017/CBO9780511804489

Brown, D. H. (2000). Principles of language learning \& teaching. (4th ed.). New York: Longman. (pp. 49-58).

Chamot, A. U. (1987). The learning strategies of ESL students. In A. Wenden \& J. Rubin (Eds.), Learner strategies in language learning (pp. 71-83). Englewood Cliffs, NJ: Prentice-Hall.

Corder, S. P. (1967). The significance of learner's errors. [Washington, D.C.]: ERIC Clearinghouse.

Corder, S. P. (1973). Introducing applied linguistics. Harmonds worth [Eng.]; Baltimore: Penguin Education.

Council of Europe. (2001). Common European framework of reference for languages: Learning, teaching, assessment. Cambridge, U.K: Press Syndicate of the University of Cambridge.

Cowan, R., Choi, H. E., \& Kim, D. H. (2003). Four questions for error diagnosis and correction in CALL. CALICO Journal, 20(3), 451-463.

Dagneaux, E., Denness, S., \& Granger, S. (1998). Computer-aided error analysis. Elsevier, 26(2), 163-174. https://doi.org/10.1016/S0346-251X(98)00001-3

Ellis, R. (1994). The Study of Second Language Acquisition. Oxford University Press, Oxford.

Engber, C. A. (1995). The relationship of lexical proficiency to the quality of ESL compositions. Journal of Second Language Writing, 4(2), 139-155. https://doi.org/10.1016/1060-3743(95)90004-7

Escure, G., \& Schwegler, A. (2004). Creoles, Contact, and Language Change: Linguistics and Social Implications: John Benjamins Pub.

Escure, G., \& Schwegler, A. (2004). Creoles, Contact, and Language Change: Linguistics and Social Implications: John Benjamins Pub.

Gentner, D., \& Boroditsky, L. (2001). Early acquisition of nouns and verbs: evidence from navajo. Routes to language: Studies in honor of Melissa Bowerman, 32-35.

Gilquin, G. (2007). To error is not all: what corpus and elicitation can reveal about the use of collocations by learners. 
Zeitschrift fuer Anglistik und Amerikanistik, 55(3), 273-291. https://doi.org/10.1515/zaa.2007.55.3.273

Gilquin, G., \& Granger, S. (2015). From design to collection of learner corpora. The Cambridge Handbook of Learner Corpus Research, 3(1), 9-34. https://doi.org/10.1017/CBO9781139649414.002

Granger, S. (2003). The International Corpus of Learner English: A New Resource for Foreign Language Learning and Teaching and Second Language Acquisition Research. TESOL Quarterly, 37(3). https://doi.org/10.2307/3588404

Grant, L., \& Ginther, A. (2000). Using computer-tagged linguistic features to describe L2 writing differences. Journal of Second Language Writing, 9, 123-145. https://doi.org/10.1016/S1060-3743(00)00019-9

Heift, T., \& Schulze, M. (2012). Errors and intelligence in computer-assisted language learning: Parsers and pedagogues. London: Routledge.

Holton, D., Mackridge, P., Philippaki-Warburton, I., \& Spyropoulos, V. (2012). Greek: A Comprehensive Grammar of the Modern Language: Taylor \& Francis.

Juozulynas, V. (1994). Errors in the Compositions of Second-Year German Students: An Empirical Study for Parser-Based ICALI. CALICO Journal, 12(1), 5-17.

Kellerman, E. (1983). Transfer and Non-Transfer: Where We Are Now. Studies in Second Language Acquisition, 2(1), 112-134.

Kızıl, A. Ş., \& Kilimci, A. (2014a). Teaching Collocations through Web-Based Concordancing: In Tafazoli \& Romero(Eds.), Multiculturalism and Technology-Enhanced Language Learning, 4, 142156. https://doi.org/10.4018/978-1-5225-1882-2.ch009

Kızıl, A. Ş., \& Kilimci, A. (2014b). Recurrent phrases in Turkish EFL learners' spoken interlanguage: A corpus-driven structural and functional analysis. Journal of Language and Linguistic Studies, 10(1), 195-210.

Mitton, R. (1996) English spelling and the computer. Harlow, Essex: Longman Group.

Moses, G. O., Joseph, O. O., \& Moses, V. O. (2014). Issues and challenges in teaching and learning of English in tertiary institutions: a case study of Kogi state college of education (technical), Kabba. International Journal of Recent Scientific Research, 5(11), 2003-2007.

Ndiaye, M., \& Faltin, A. V. (2003). A Spell Checker Tailored to Language Learners. Computer Assisted Language Learning, 16(2-3), 213-232. https://doi.org/10.1076/call.16.2.213.15881

Olsen, K. A. (1999). An international perspective authors. Journal of the Association for Information Science and Technology.

Pantel, P., \& Chklovski, T. (2004). VerbOcean: Mining the web for fine-grained semantic verb relations. EMNLP, 4 , 33-40.

Richards, J. C. (1971). 'A Non-Contrastive Approach to Error-Analysis,' English Language Teaching, 25, 204-219. https://doi.org/10.1093/elt/XXV.3.204

Schachter, J. (1974). An error in error analysis. Language Learning, 24, 205-214. https://doi.org/10.1111/j.1467-1770.1974.tb00502.x

Schuler, K. K. (2005). VerbNet: a broad-coverage, comprehensive verb lexicon. Penn Libraries, University of Pennsylvania.

Sinclair, J. M. (2001). The deification of information' in Thompson and Scott (eds), Patterns of Text, 287-313.

Stapa, S., Izaha, M., (n.d). (2010). Analysis of errors in subject - verb agreement among Malaysian ESL learners: The Southeast Asian Journal of English Language Studies, 16(1).

Swan, M., \& Smith, B. (2001). Learner English: A teacher's guide to interference and other problems. Cambridge: Cambridge University Press. https://doi.org/10.1017/CBO9780511667121

Taylor, B. (1975). The use of overgeneralization and transfer learning strategies by elementary and intermediate students of ESL. Language Learning, 25(1), 73-107. https://doi.org/10.1111/j.1467-1770.1975.tb00110.x

\section{Copyrights}

Copyright for this article is retained by the author(s), with first publication rights granted to the journal.

This is an open-access article distributed under the terms and conditions of the Creative Commons Attribution license which permits unrestricted use, distribution, and reproduction in any medium, provided the original work is properly cited. 